\title{
A novel minimally invasive near-infrared thoracoscopic localization technique of small pulmonary nodules: A phase I feasibility trial
}

\author{
Hideki Ujiie, MD, PhD, ${ }^{a}$ Tatsuya Kato, MD, PhD, ${ }^{a}$ Hsin-pei Hu, MHSc, ${ }^{\text {a }}$ Priya Patel, MD, ${ }^{a}$ \\ Hironobu Wada, MD, PhD, ${ }^{a}$ Kosuke Fujino, MD, PhD, ${ }^{a}$ Robert Weersink, PhD,${ }^{b, c}$ Elsie Nguyen, MD, ${ }^{d}$ \\ Marcelo Cypel, MD, MSc, ${ }^{a}$ Andrew Pierre, MD, MSc, ${ }^{a}$ Marc de Perrot, MD, MSc, ${ }^{a}$ Gail Darling, MD, \\ Thomas K. Waddell, MD, PhD, ${ }^{\mathrm{a}}$ Shaf Keshavjee, MD, MSc, ${ }^{a}$ and Kazuhiro Yasufuku, MD, PhD ${ }^{\mathrm{a}, \mathrm{b}}$
}

\begin{abstract}
Objectives: Localization and resection of nonvisible, nonpalpable pulmonary nodules during video-assisted thoracoscopic surgery are challenging. Our study was to determine the feasibility and safety of indocyanine green fluorescence localization and resection of small nodules using a near-infrared fluorescence thoracoscope.

Methods: Twenty patients with undiagnosed peripheral nodules smaller than $3 \mathrm{~cm}$ scheduled for computed tomography-guided microcoil placement followed by video-assisted thoracoscopic surgery wedge resection were enrolled. After microcoil deployment, 100 to $150 \mu \mathrm{L}$ of diluted indocyanine green was injected percutaneously near the nodule. The nodule initially was localized solely by using a near-infrared thoracoscope to visualize indocyanine green fluorescence. Thoracoscopic instruments were used to determine the staple line. Wedge resection was performed after confirmation of the location of the microcoil using fluoroscopy.
\end{abstract}

Results: Twenty patients underwent near-infrared, image-guided, video-assisted thoracoscopic surgery resection. The median computed tomography tumor size was $1.2 \mathrm{~cm}$. The median depth from the pleural surface was $1.4 \mathrm{~cm}$ (range, $0.2-$ $4.8 \mathrm{~cm}$ ). The median computed tomography-guided intervention time was $35 \mathrm{mi}-$ nutes, and video-assisted thoracoscopic surgery procedural time was 54 minutes. Indocyanine green fluorescence was clearly identified in 18 of 20 patients $(90 \%)$. The surgical margins were all negative on final pathology without the need for additional resection. The final diagnoses included 18 primary lung cancers, 1 metastatic lung cancer, and 1 benign lung tumor.

Conclusions: Computed tomography-guided percutaneous indocyanine green injection and intraoperative near-infrared localization of small nodules are safe and feasible. These offer surgeons the ease of localization through direct indocyanine green fluorescence imaging without the use of fluoroscopy and may be a complementary technique to preoperative microcoil placement for nonvisible, nonpalpable intrapulmonary nodules. (J Thorac Cardiovasc Surg 2017;154:702-11)

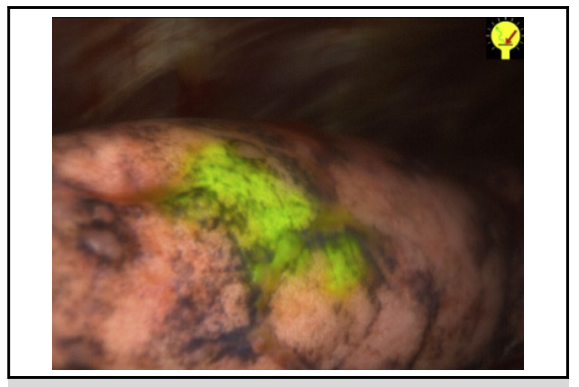

Intraoperative image of fluorescent ICG with a NIR thoracoscope.

\section{Central Message}

Intraoperative NIR thoracoscopic localization using ICG injection is a safe and feasible procedure.

\section{Perspective}

CT-guided percutaneous ICG injection and intraoperative NIR thoracoscopic localization of small pulmonary nodules are safe and feasible minimally invasive procedures. They offer surgeons the ease of localization through direct ICG fluorescence imaging without using fluoroscopy and are complementary to preoperative microcoil placement.

See Editorial Commentary page 712.
From the a Division of Thoracic Surgery, Toronto General Hospital, ${ }^{\mathrm{b}}$ TECHNA Institute, ${ }^{\mathrm{c}}$ Department of Radiation Oncology, and ${ }^{\mathrm{d}}$ Division of Cardiothoracic Imaging, Joint Department of Medical Imaging, University Health Network, University of Toronto, Toronto, Ontario, Canada.

Funding support: Novadaq Technologies Inc provided the PINPOINT thoracoscope and indocyanine green for this work. Siemens Inc provided partial salary support for R.W. H.U. received a research scholarship from the Joseph M. West Family Memorial Fund. Clinical Trial Registry Number: NCT02090660.

Approvals: A Health Canada No Objection Letter was obtained for the off-label use of indocyanine green (\#9427-D2777-21C). An Investigational Testing AuthorizationClass II was obtained (\#219223) for the use of the near-infrared fluorescence thoracoscope (Pinpoint System, Novadaq Technologies Inc, Mississauga, Ontario,
Canada). This study was approved by the Institutional Review Board of the University Health Network (REB \#12-5454).

Read at the 96th Annual Meeting of The American Association for Thoracic Surgery, May 14-18, 2016, Baltimore, Maryland.

Received for publication May 24, 2016; revisions received Feb 12, 2017; accepted for publication March 6, 2017; available ahead of print May 9, 2017.

Address for reprints: Kazuhiro Yasufuku, MD, PhD, Division of Thoracic Surgery, University of Toronto, Toronto General Hospital, 200 Elizabeth St, 9N-957, Toronto, Ontario M5G2C4, Canada (E-mail: kazuhiro.yasufuku@uhn.ca). $0022-5223 / \$ 36.00$

Copyright (C) 2017 by The American Association for Thoracic Surgery http://dx.doi.org/10.1016/j.jtcvs.2017.03.140 


\section{Abbreviations and Acronyms}

$\mathrm{CT}=$ computed tomography

$\mathrm{C} / \mathrm{T}=$ consolidation/tumor

ICG = indocyanine green

NIR $=$ near-infrared

VATS $=$ video-assisted thoracoscopic surgery

Scanning this QR code will take you to supplemental videos. To view the AATS 2016 Webcast, see the URL next to the webcast thumbnail.

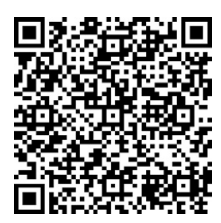

Lung cancer is the leading cause of cancer death in many parts of the world. ${ }^{1}$ With the application of computed tomography (CT) to lung cancer screening, sub-centimeter pulmonary nodules are frequently detected. ${ }^{2,3}$ A recent clinical trial has demonstrated the efficacy of low-dose CT screening for high-risk individuals, potentially increasing the expected detection rate of early-stage lung cancer. ${ }^{4}$ Early diagnosis of lung cancer can lead to more treatment options, less-invasive surgery, and a higher survival. In addition, minimally invasive surgery, including video-assisted thoracoscopic surgery (VATS), has been known to be ideal for resection of small nodules, because it results in minimal postoperative morbidity and mortality along with less pain and a better quality of life than with an open thoracotomy. ${ }^{5,6}$ However, localizing the small-sized pulmonary nodules during VATS is challenging when no changes appear on visceral pleura. ${ }^{7,8}$ Inadequate nodule localization may lead to prolonged operative time while searching for the nodule or result in conversion to an unplanned open thoracotomy. ${ }^{7-9}$ Inadequate tumor margins increase local recurrence rates with the potential for microscopic spread of cancer cells from the surgical margin. ${ }^{10,11}$ With the current shift toward minimally invasive surgery, intraoperative localization of small lung nodules has become a critical challenge. Preoperative localization techniques have been introduced as a method of improving the success rates of VATS and preventing unwanted thoracotomy. ${ }^{7,8}$ Microcoil and hook wire have been used to localize the pulmonary nodules using the CT-guided percutaneous approach before surgery and are visualized by fluoroscopy and thoracoscopy during surgery. ${ }^{9,12-17}$ The standard procedure at Toronto General Hospital for intraoperative localization of small-sized nodules is CT-guided metallic microcoil placement performed before VATS. ${ }^{13-15}$ Preoperative CT-guided placement of a metallic object with intraoperative fluoroscopic assistance has become the prevalent method of localizing small pulmonary nodules and has been highly successful in localizing nodules, with success rates greater than $97 \%{ }^{13-15}$ The microcoil is then visualized with fluoroscopy intraoperatively and resected together with the pulmonary nodule. However, the metal tag placement procedure requires a preoperative invasive procedure that can result in patient discomfort, and complications such as metal tag dislodgement, pneumothorax, and hemoptysis may occur. Furthermore, use of fluoroscopy makes intraoperative radiation exposure inevitable for both patients and operating room staff.

In a previous animal study, we demonstrated a novel near-infrared (NIR) thoracoscopic lung nodule localization technique using injection of fluorescent indocyanine green (ICG). ${ }^{18}$ We have been working on the translation of the novel technique into a clinical setting. The purpose of the current study is to determine the feasibility and safety of ICG fluorescence localization for resection of small pulmonary nodules with a NIR fluorescence thoracoscope in a phase I feasibility study.

\section{MATERIALS AND METHODS}

\section{Study Plan and Patient Groups}

This prospective phase I clinical trial used ICG for "off-label use" as an intraparenchymal injection, and a Health Canada No Objection Letter was obtained (\#9427-D2777-21C). An Investigational Testing AuthorizationClass II was obtained (\#219223) for the use of the near-infrared (NIR) fluorescence thoracoscope (Pinpoint System; Novadaq Technologies Inc, Mississauga, Ontario, Canada). This study was approved by the Institutional Review Board of the University Health Network, and all patients gave informed consent (REB \#12-5454). The inclusion criteria for our phase I study (NCT02090660) were patients with undiagnosed peripheral

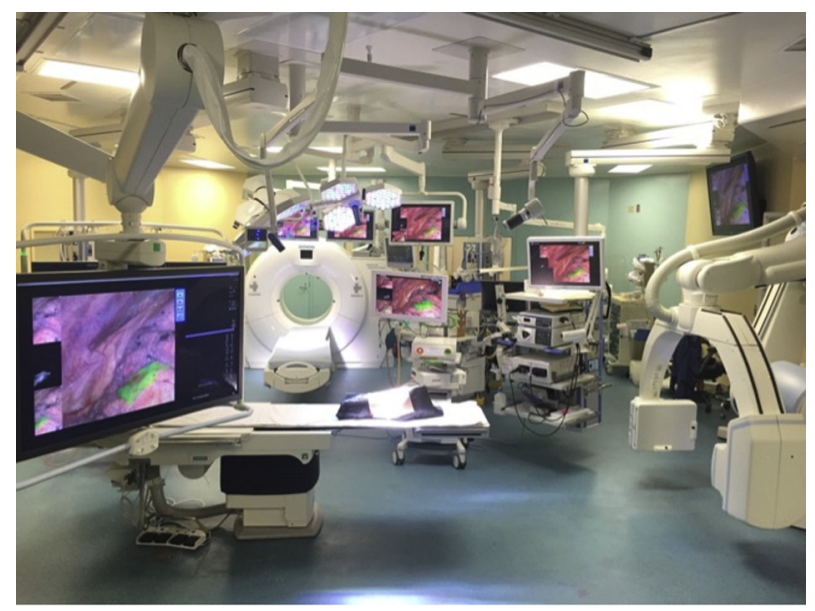

FIGURE 1. The guided therapeutic operating room equipped with imagebased surgical navigation technologies, including the dual-source dualenergy CT scanner (Definition FLASH CT; Siemens, Washington, DC), robotic cone-beam CT (Artis Zeego, Siemens), endoscopy, and tracking/ navigation systems. 


\section{CT-guided microcoil insertion and ICG injection}
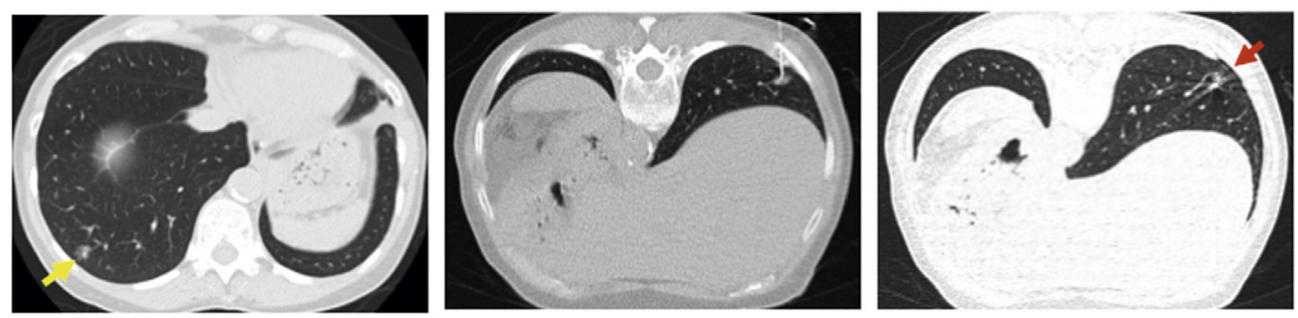

A

Microcoil placement

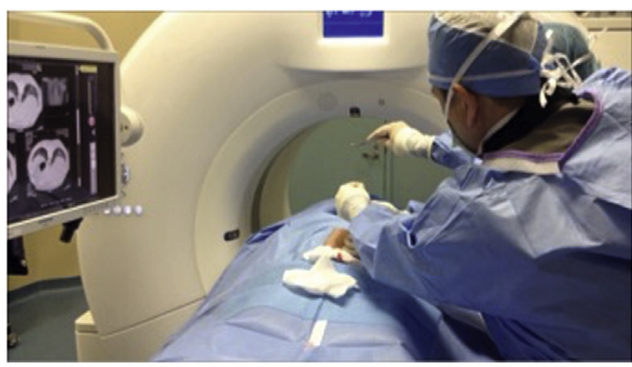

ICG injection

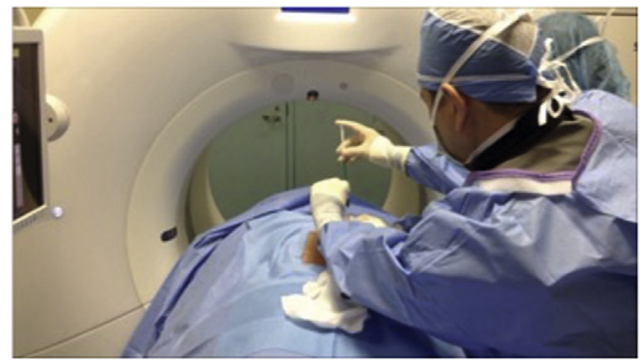

B

FIGURE 2. A, CT-guided microcoil insertion and ICG injection. *Yellow arrow: lung nodule. *Red arrow: microcoil. B, Procedure image, microcoil insertion (left), ICG injection (right). CT, Computed tomography; ICG, indocyanine green.

nodules that were smaller than $3 \mathrm{~cm}$ scheduled for CT-guided microcoil placement followed by VATS wedge resection. Patients with suspicious mediastinum on CT or positron emission tomography scan underwent preoperative endobronchial ultrasound transbronchial aspiration to confirm that the mediastinal lymph nodes were clear of disease. ${ }^{19}$ Our exclusion criteria were (1) patients with an allergy to iodine, shellfish, cough mixture, Betadine, or other iodine contrast agents; and (2) pregnant or potentially pregnant women.

\section{Materials}

The ICG (IC-Green; Akorn, Inc, Lake Forest, Ill) is a water-soluble anionic, amphiphilic NIR fluorophore with an excitation wavelength of $790 \mathrm{~nm}$, an emission wavelength of $830 \mathrm{~nm}$, and a molecular weight of $774.9 \mathrm{kDa}$. A dose of 100 to $150 \mu \mathrm{L}$ of ICG at a concentration of $1.25 \times 10^{-1} \mathrm{mg} / \mathrm{mL}$ was injected into the lung parenchyma percutaneously under CT guidance. The ICG dose and concentration were selected on the basis of our preclinical studies to exhibit high fluorescence intensity. ${ }^{18}$ The ICG fluorescence in the lung tissue was captured by the NIR thoracoscope. This is a Food and Drug Administration and Health Canada-approved rigid thoracoscope, which has a $10-\mathrm{mm}$ diameter and a $30-\mathrm{cm}$ length in a straight, rigid scope. The optical system has a 0 -degree or 30 -degree view angle, and a 70-degree field of view, transmitting both visible light and $808 \mathrm{~nm} \pm 5 \mathrm{~nm}$ NIR laser. The laser power is classified as class $3 R$ at the tip of the scope as per the International Electro-Technical Commission IEC60825-1. Pulse duration is $17 \mathrm{~ms}$ in the maximum setting at 20 pulses per second.

\section{Procedure}

The purpose of this study was to determine the feasibility of using ICG to localize nodules. All surgical procedures were performed in the multimodal image-guided operating room called the "guided therapeutic operating room" at Toronto General Hospital equipped with image-based surgical navigation technologies, including a dual-source dual-energy CT scanner (Definition FLASH CT; Siemens, Washington, DC), a robotic cone-beam CT (Artis Zeego, Siemens), endoscopy, and tracking/navigation systems (Figure 1). With the use of a local anesthetic, sterile, and coaxial technique with an outer 19-gauge needle, a Boston Scientific (Marlborough, Mass) Vortex microcoil was delivered through a 22gauge Chiba needle. The microcoil was deployed entirely proximal to the nodule as previously reported without marking of the visceral pleural surface. ${ }^{14}$ After deployment of the coil, 100 to $150 \mu \mathrm{L}$ of diluted ICG at a concentration of $1.25 \times 10^{-1} \mathrm{mg} / \mathrm{mL}$ was injected using a separate 22gauge Chiba needle through the same outer 19-gauge needle (Figure 2 and Video 1). After confirmation of a satisfactory microcoil position on $\mathrm{CT}$, the patient was transferred to the cone-beam CT table and underwent induction with general anesthesia. After commencing VATS, the NIR thoracoscope was used to localize the nodule with ICG fluorescence (Figure 3, A, and Video 2). Thoracoscopic instruments were used to clamp the lung to set an imaginary staple line for the intended resection

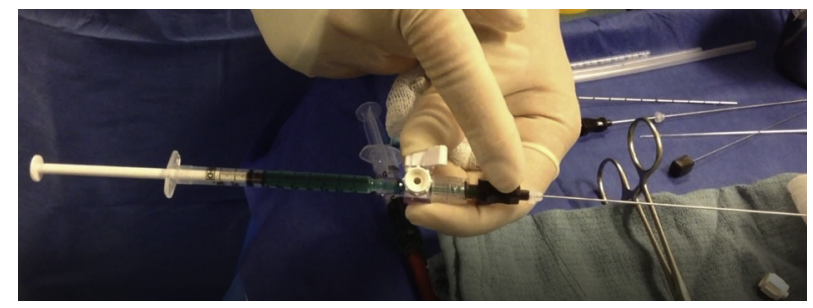

VIDEO 1. Preoperative CT-guided microcoil placement and ICG injection. Video available at: http://www.jtcvsonline.org/article/S00225223(17)30701-8/addons. 


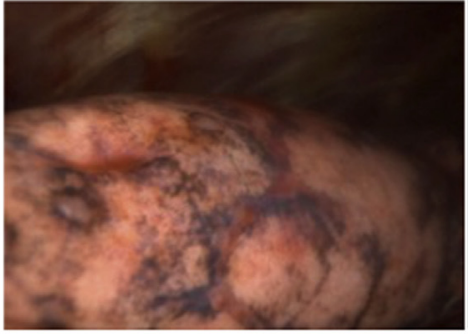

A

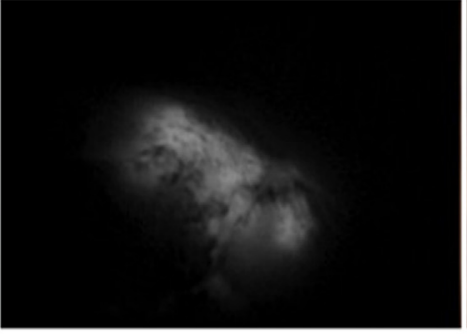

Fluorescence (FL) image

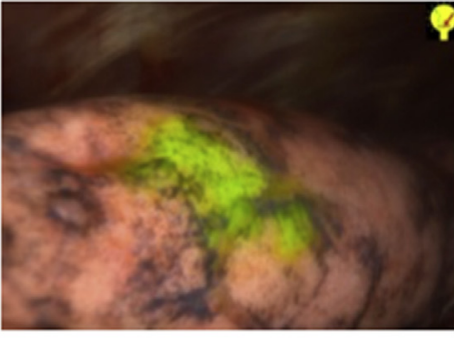

WL-FL merge image
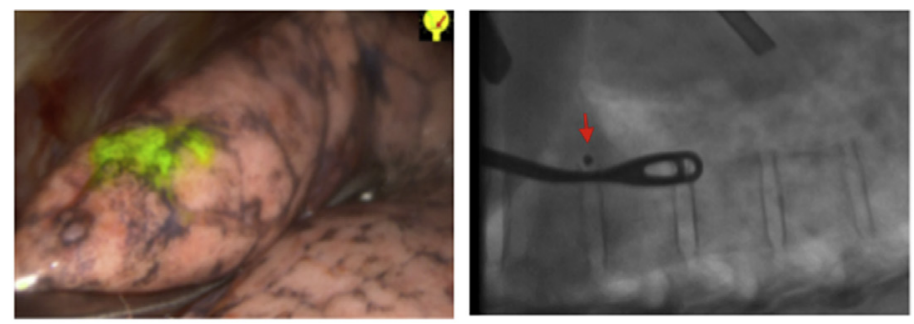

B

WL-FL merge image

\section{X-ray fluoroscopy image}

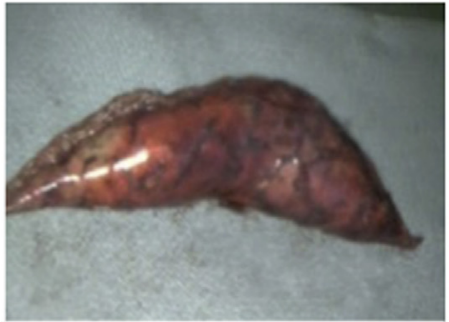

White light $(W L)$ image

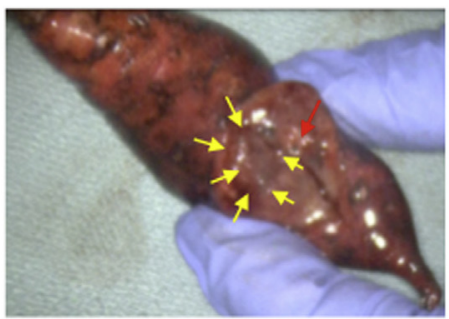

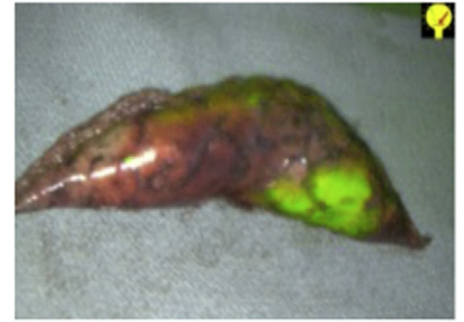

WL-FL merge image

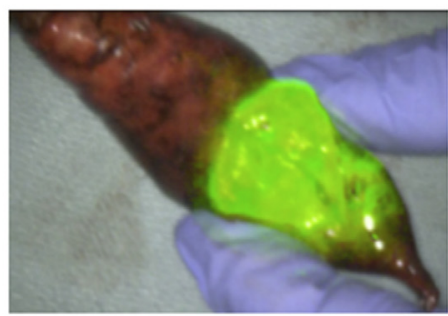

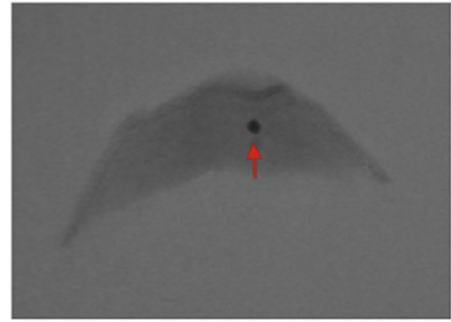

X-ray fluoroscopy image

C

FIGURE 3. A, Intraoperative imaging using a NIR thoracoscope. White light image, NIR fluorescence image, white light, and fluorescence merge image. $\mathrm{B}$, Thoracoscopic instrument was used to clamp the lung to set an imaginary staple line for the intended resection. X-ray fluoroscopy was then used to identify the location of the microcoil relative to the instrument. C, Resected specimen. The microcoil in the resected specimen was localized using X-ray fluoroscopy. *Yellow arrow: lung nodule. *Red arrow: microcoil.

(Figure 3,B). X-ray fluoroscopy was then used to confirm the location of the microcoil in relation to the instrument, and surgical staplers were then used to carry out the VATS wedge resection. Finally, the microcoil was localized using intraoperative fluoroscopy as the standard of care, and the lesion was removed together with the lung parenchyma and the entire microcoil (Figure 3,C). After resection, the specimen was cut along the maximum diameter of the lung tumor, observed with the NIR thoracoscope, and the surgical margin was inspected macroscopically. If the surgical margin was close to the tumor macroscopically, an additional resection was performed and sent for pathologic evaluation. All tumors were reviewed by specialized lung pathologists.

\section{Outcome Measures}

The primary objective of this study was to demonstrate the feasibility and safety of our novel fluorescent localization method with ICG and the NIR fluorescence thoracoscope system. With subsequent studies, we hope to prove that this technique is a procedure comparable to the conventional CT-guided percutaneous metallic microcoil implantation method.

\section{RESULTS}

Between May 2014 and March 2016, 20 patients with small peripheral nodules suspicious for malignancy 


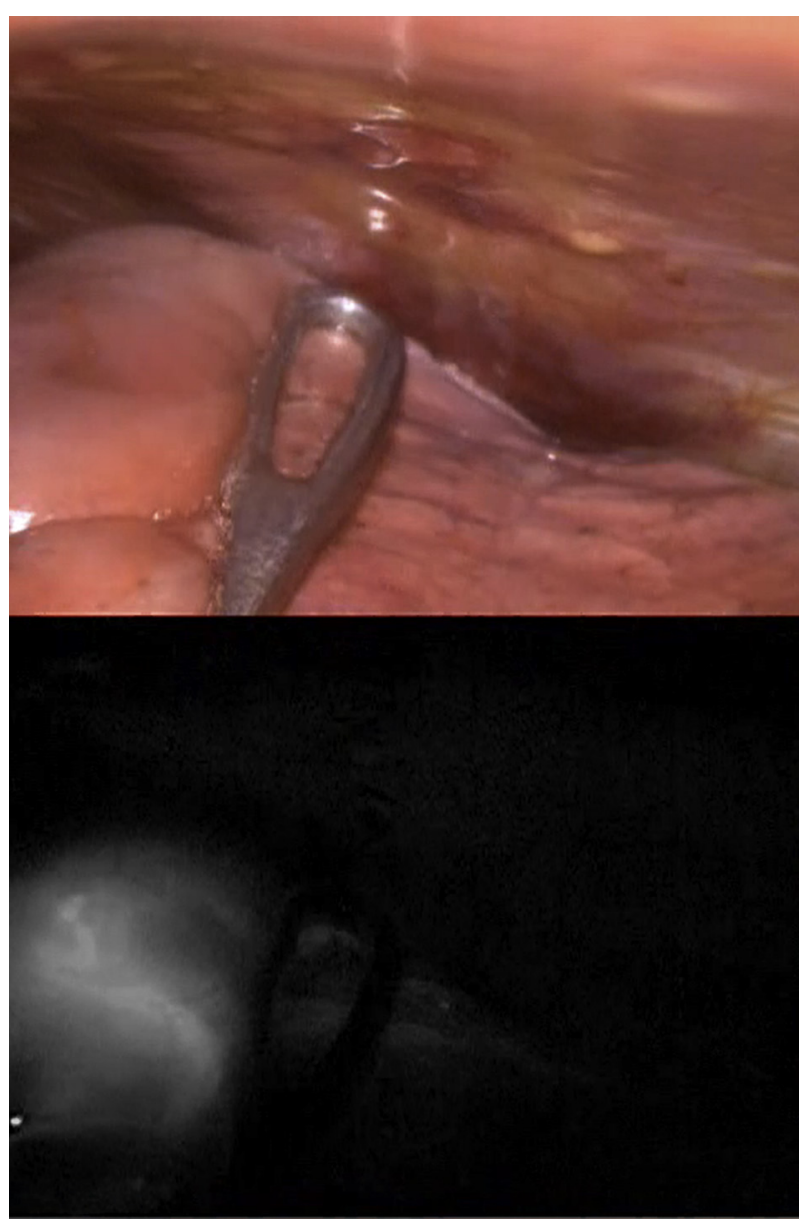

VIDEO 2. Intraoperative NIR localization of small lung nodules. Video available at: http://www.jtcvsonline.org/article/S0022-5223(17)30701-8/ addons.

underwent CT-guided placement of microcoil and injection of ICG followed by NIR image-guided VATS resection. All operations described in this trial were wedge resections. The patient characteristics are summarized in Table 1 . The demographic information is listed in Table 2. There were 10 female patients and 10 male patients with a mean age of 69.5 years (range, 54-82 years). On CT, there were 4 solid nodules $(<50 \%$ consolidation/tumor $[\mathrm{C} / \mathrm{T}]$ ratio $\leq 100 \%)$, 5-part solid ground-glass nodules $(<0 \% \mathrm{C} / \mathrm{T}$ ratio $\leq 50 \%)$, and 11 pure ground-glass nodules $(\mathrm{C} / \mathrm{T}$ ratio $=0 \%$ ). The median $\mathrm{CT}$ tumor size was $1.2 \mathrm{~cm}$ (range, $0.5-2.4 \mathrm{~cm}$ ), and pathologic tumor size of 20 cases was $1.1 \mathrm{~cm}$ (range, $0.5-2.4 \mathrm{~cm}$ ). The median distance from the pleural surface to the nodal surface was $1.4 \mathrm{~cm}$ (range, $0.2-4.8 \mathrm{~cm}$ ). The median distance from the pleura surface to the deepest tumor boundary was $2.6 \mathrm{~cm}$ (range, 0.8$5.8 \mathrm{~cm}$ ). The mean CT-guided intervention time was $35 \mathrm{mi}-$ nutes (range, 19-59 minutes), and VATS wedge resection procedural time was 54 minutes (range, 28-84 minutes). ICG was successfully injected in all patients. In 4 patients in whom there was suspicion of mediastinal lymph node
TABLE 1. Patient characteristics and tumor data

\begin{tabular}{lc}
\hline \multicolumn{1}{c}{ Patient characteristics and tumor variables } & Value $(\mathbf{n}=\mathbf{2 0})$ \\
\hline Median age (range), y & $68.5(54-82)$ \\
Gender & \\
Male & 10 \\
Female & 10 \\
Median CT nodule size (range), cm & $1.2(0.5-2.4)$ \\
Median CT nodule depth from surface (range), cm & $1.4(0.2-4.8)$ \\
Nodule location & \\
Right upper lobe & 8 \\
Right middle lobe & 1 \\
Right lower lobe & 3 \\
Left upper lobe & 6 \\
Left lower lobe & 2 \\
CT findings & \\
Pure GGN & 11 \\
Part solid GGN & 5 \\
Solid nodule & 4 \\
Median pathologic tumor size, cm (range)* & $1(0.5-2.4)$ \\
Pathologic diagnosis* & \\
Adenocarcinoma & 16 \\
$\quad$ Adenocarcinoma in situ & 6 \\
Minimally invasive adenocarcinoma & 2 \\
Lepidic predominant adenocarcinoma & 1 \\
Acinar predominant adenocarcinoma & 1 \\
Squamous cell carcinoma & \\
Small cell carcinoma & \\
Focal perivascular lymphoid infiltrate & 4 \\
Metastatic lung tumor* & 1 \\
\hline
\end{tabular}

$C T$, Computed tomography; $G G N$, ground-glass nodule. * Metastatic lung tumor from colon cancer.

metastasis, we performed preoperative endobronchial ultrasound transbronchial aspiration for mediastinal staging. During surgery, ICG fluorescence was clearly identified in all but 2 patients (18/20: 90\%) (Figure 4). In 18 cases, NIR thoracoscope was solely used to successfully localize and resect the nodule without the need of fluoroscopy. In 1 patient in whom a nodule $1.0 \mathrm{~cm}$ in size was located $4.8 \mathrm{~cm}$ from the pleura, ICG fluorescence was not detected, and therefore localization was performed with microcoil and fluoroscopy (Case 19). We were unable to detect ICG fluorescence in 1 patient (Case 20) in whom we had difficulties deflating the lung possibly because of dislodging of the double-lumen endotracheal tube. In this case, the microcoil with fluoroscopy was used for localization and resection of the nodule. After wedge resection, we confirmed NIR fluorescence in the resected specimen. In all cases, the target nodule was successfully removed with negative surgical margins, and ICG fluorescence was clearly detected in the resected specimen. There were no adverse effects related to ICG injection. We performed intraoperative lymph node sampling in 3 cases to confirm negative lymph node metastasis. There were no perioperative or postoperative complications. All patients were 


\begin{tabular}{|c|c|c|c|c|c|c|c|c|c|c|c|c|}
\hline \multirow[b]{2}{*}{$\begin{array}{c}\text { Case } \\
\text { no. }\end{array}$} & \multirow[b]{2}{*}{$\begin{array}{c}\text { ICG } \\
\text { fluorescence }\end{array}$} & \multirow[b]{2}{*}{ Gender } & \multirow[b]{2}{*}{$\begin{array}{l}\text { Age } \\
(y)\end{array}$} & \multirow[b]{2}{*}{$\begin{array}{c}\text { Tumor } \\
\text { location }\end{array}$} & \multicolumn{5}{|c|}{ CT finding } & \multirow{2}{*}{\multicolumn{2}{|c|}{$\begin{array}{l}\text { Pathologic } \\
\text { closest } \\
\text { resection } \\
\text { margin }(\mathbf{c m})\end{array}$}} & \multirow[b]{2}{*}{$\begin{array}{c}\text { Pathologic } \\
\text { diagnosis }\end{array}$} \\
\hline & & & & & $\begin{array}{l}\text { Image } \\
\text { finding }\end{array}$ & $\begin{array}{l}\text { Tumor } \\
\text { size } \\
(\mathbf{c m}) \\
\end{array}$ & $\begin{array}{c}\mathrm{C} / \mathrm{T} \\
\text { ratio }(\%)\end{array}$ & $\begin{array}{c}\text { Tumor } \\
\text { depth } \\
(\mathrm{cm})\end{array}$ & $\begin{array}{c}\text { Deepest } \\
\text { tumor } \\
\text { depth } \\
(\mathrm{cm})\end{array}$ & & & \\
\hline 1 & Clear & $\mathrm{F}$ & 70 & LUL & $\begin{array}{l}\text { Part solid } \\
\text { GGN }\end{array}$ & 1.3 & 15 & 1.8 & 2.6 & 1 & 0.4 & $\begin{array}{l}\text { Adenocarcinoma } \\
\text { (ACI) }\end{array}$ \\
\hline 2 & Clear & M & 64 & LUL & $\begin{array}{l}\text { Part solid } \\
\text { GGN }\end{array}$ & 0.9 & 11 & 0.9 & 1.5 & 0.8 & 1.0 & $\begin{array}{l}\text { Adenocarcinoma } \\
\text { (ACI) }\end{array}$ \\
\hline 3 & Clear & M & 73 & LUL & Solid nodule & 0.9 & 100 & 1.9 & 2.8 & 1.2 & 0.9 & $\begin{array}{l}\text { Metastatic lung } \\
\text { tumor* }\end{array}$ \\
\hline 4 & Clear & M & 56 & RML & Pure GGN & 1 & 0 & 1.5 & 2.5 & 0.7 & 0.7 & $\begin{array}{l}\text { Focal perivascular } \\
\text { lymphoid } \\
\text { infiltrates }\end{array}$ \\
\hline 5 & Clear & $\mathrm{F}$ & 73 & LLL & Pure GGN & 0.5 & 0 & 0.2 & 0.8 & 0.5 & 1.0 & AIS \\
\hline 6 & Clear & M & 75 & RLL & Solid nodule & 1.1 & 100 & 1.8 & 2.8 & 1.2 & 0.6 & $\begin{array}{l}\text { Squamous cell } \\
\text { carcinoma }\end{array}$ \\
\hline 7 & Clear & $\mathrm{F}$ & 67 & RLL & $\begin{array}{l}\text { Part solid } \\
\text { GGN }\end{array}$ & 1.1 & 9 & 0.2 & 1.6 & 0.9 & 1.3 & MIA \\
\hline 8 & Clear & M & 69 & LUL & Pure GGN & 1.5 & 0 & 0.5 & 2.2 & 1 & 2.5 & AIS \\
\hline 9 & Clear & M & 75 & RUL & $\begin{array}{l}\text { Part solid } \\
\text { GGN }\end{array}$ & 2.4 & 50 & 3.7 & 5.1 & 2.3 & 0.5 & $\begin{array}{l}\text { Adenocarcinoma } \\
\text { (LEP) }\end{array}$ \\
\hline 10 & Clear & $\mathrm{F}$ & 82 & RUL & Solid GGN & 1.6 & 63 & 2.5 & 4.5 & 2.4 & 1.4 & $\begin{array}{l}\text { Adenocarcinoma } \\
\text { (LEP) }\end{array}$ \\
\hline 11 & Clear & M & 54 & LLL & Pure GGN & 1.3 & 0 & 0.9 & 1.8 & 0.8 & 0.7 & AIS \\
\hline 12 & Clear & $\mathrm{F}$ & 65 & RUL & Pure GGN & 2.3 & 0 & 2.7 & 4.6 & 1.6 & 0.7 & $\begin{array}{l}\text { Adenocarcinoma } \\
\text { (LEP) }\end{array}$ \\
\hline 13 & Clear & $\mathrm{F}$ & 68 & RLL & Pure GGN & 0.9 & 0 & 1.1 & 2.3 & 0.8 & 1 & AIS \\
\hline 14 & Clear & M & 60 & RUL & Solid nodule & 0.9 & 89 & 1.9 & 2.8 & 1 & 1.7 & SCLC, LCNEC \\
\hline 15 & Clear & $\mathrm{F}$ & 69 & RUL & Pure GGN & 0.6 & 0 & 1.7 & 2.9 & 2 & 0.3 & AIS \\
\hline 16 & Clear & M & 81 & LUL & Pure GGN & 1.4 & 0 & 1.2 & 2.6 & 1.6 & 1.0 & $\begin{array}{l}\text { Adenocarcinoma } \\
\text { (LEP) }\end{array}$ \\
\hline 17 & Clear & $\mathrm{F}$ & 71 & RUL & $\begin{array}{l}\text { Part solid } \\
\text { GGN }\end{array}$ & 1.4 & 29 & 0.9 & 2.3 & 1.3 & 1.2 & $\begin{array}{l}\text { Adenocarcinoma } \\
\text { (ACI) }\end{array}$ \\
\hline 18 & Clear & M & 74 & LUL & Pure GGN & 1.6 & 0 & 1.2 & 2.8 & 1.2 & 0.8 & AIS \\
\hline 19 & Unclear & $\mathrm{F}$ & 59 & RUL & Pure GGN & 1 & 0 & 4.8 & 5.8 & 0.8 & 1.4 & $\begin{array}{l}\text { Adenocarcinoma } \\
\text { (ACI) }\end{array}$ \\
\hline 20 & Non-detect & $\mathrm{F}$ & 71 & RUL & Pure GGN & 1.6 & 0 & 0.9 & 2.5 & 1.7 & 0.4 & MIA \\
\hline
\end{tabular}

discharged from the hospital without any complication related to the procedure.

The final diagnoses of the 20 cases included 16 adenocarcinomas $(80 \%), 1$ metastatic lung cancer from colon cancer $(5 \%), 1$ squamous cell carcinoma (5\%), 1 small cell carcinoma, and 1 focal perivascular lymphoid infiltrate $(5 \%)$. Among the 16 primary pulmonary adenocarcinoma cases, 6 were adenocarcinoma in situ, 2 were minimally invasive adenocarcinoma, 4 were lepidic predominant adenocarcinoma, and 4 were acinar predominant adenocarcinoma (Table 1). The surgical margin of all wedge resection specimens were negative microscopically without additional resection of lung parenchyma.

\section{DISCUSSION}

In our phase I clinical trial, 20 patients with solitary pulmonary nodule underwent VATS wedge resection after ICG injection. The NIR signal detected $90 \%$ of these tumors without complications. On the basis of our study, CTguided percutaneous ICG injection with intraoperative NIR localization of small nodules was a safe and feasible procedure during minimally invasive surgery. It offers surgeons the ease of localization through direct ICG fluorescence imaging without the use of fluoroscopy and appears to be equivalent in localization accuracy to preoperative microcoil placement for nonvisible, nonpalpable intrapulmonary nodules. 

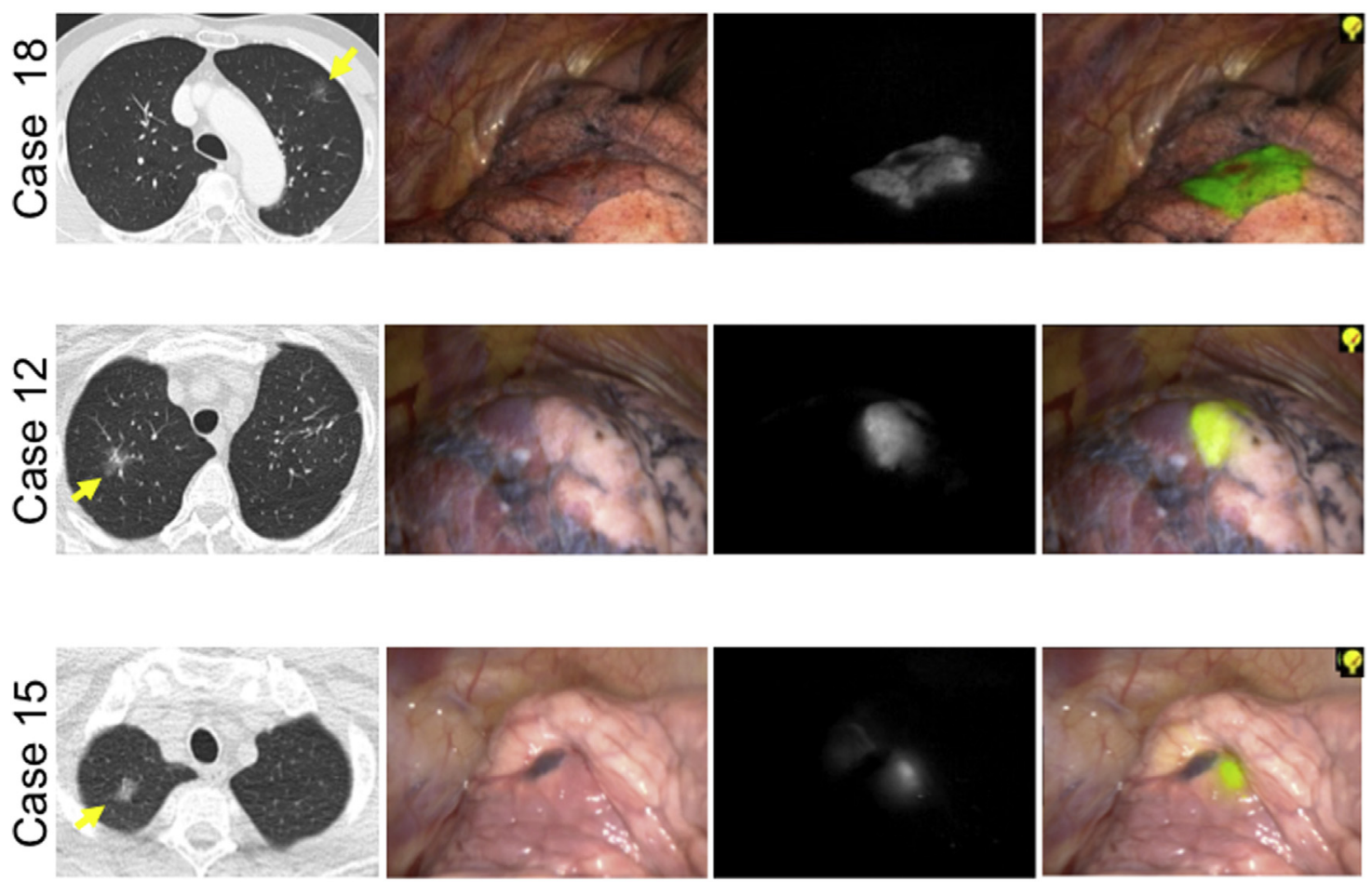

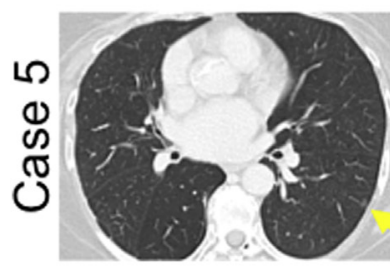

CT image

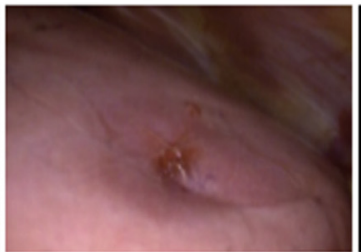

White light (WL) image

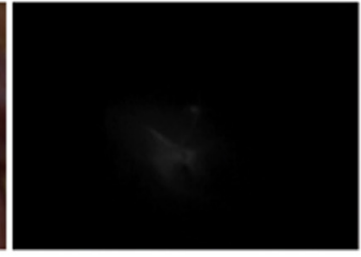

Fluorescence (FL) image

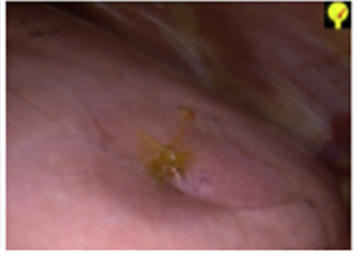

WL-FL merge image

FIGURE 4. CT scan and thoracoscopic images of representative cases. First column: CT image. Preoperative CT scan of the chest. The yellow arrow points to the tumor. Intraoperative thoracoscopic white light image, NIR fluorescence image, and white light-fluorescence merge image using NIR thoracoscope are shown in the subsequent columns. $C T$, Computed tomography.

ICG is approved by the Food and Drug Administration as an intravenously injectable drug for indications and use, such as determining cardiac output, hepatic function, and liver blood flow, and for ophthalmic and cardiovascular angiography. ICG also has been used for sentinel lymph node detection of skin melanoma, ${ }^{20-22}$ breast cancer, ${ }^{23-25}$ gynecologic carcinoma,${ }^{26}$ head and neck carcinoma, ${ }^{27}$ and lung cancer. ${ }^{28}$ In the current study, we used new NIR thoracoscope technology with the ability to simultaneously display and overlay fluorescence image and white light image during VATS (PINPOINT Endoscopic Fluorescence Imaging; Novadaq Technologies Inc, Mississauga, Ontario, Canada). NIR imaging using ICG fluorescence has several unique advantages compared with other techniques. The excitation of ICG by a class 3 laser light and the deep tissue penetration properties of NIR emission light both contribute to the visualization of the small amount of diluted ICG within the lung parenchyma. It does not require radiation. The excitation energy for exciting NIR contrast agents is low $\left(10^{-1} \mathrm{eV}\right)$ and has less energy than the lights in an operating room; thus, it is safe for humans without shielding. The ICG fluorescence penetrating the lung tissue was successfully captured by the NIR thoracoscope in 18 of 20 cases and was detected regardless of the color of the lung surface. Unlike color dye detection by a white light endoscope, the specific wavelength of ICG fluorescence is always detectable regardless of any changes in color or texture of the visceral pleura, which may occur as the result of anthracosis or other underlying pulmonary diseases. ICG fluorescence imaging is easy to understand, real-time, and 
intuitive for the observer. Furthermore, ICG is safe and does not necessarily have to be removed from lung tissue. This characteristic offers ICG an advantage compared with other fiducial markers that must be removed together with the pulmonary nodules during surgery, including liquid markers such as radiotracer, iodine, and barium.

\section{Study Limitations}

We acknowledge that the present method has limitations and thus room for technical improvement. In this study, 1 case required a combination of NIR imaging and fluoroscopy for localization of the microcoil because of insufficient ICG fluorescence. In this case, the lung nodule was situated $4.8 \mathrm{~cm}$ from the needle insertion point on the lung surface. In our preclinical study, tissue penetration of the NIR fluorescence image was limited at depths more than $24 \mathrm{~mm} .{ }^{18}$ Thus, the fluorescence in this case was probably out of range for detection from the lung surface. In another case, we were unable to detect ICG fluorescence because of incomplete deflation of the lung caused by inadequate double-lumen bronchial tube placement. In lungs with air volume retention, it is difficult to see ICG fluorescence. ${ }^{18}$ There were no adverse outcomes for the patient because we were able to use the microcoil for localization. On examination of the resected specimen, ICG fluorescence was clearly detected near the microcoil and the tumor. As demonstrated in these cases, the depth of the lesion and complete deflation of the lung are important factors for optimal ICG fluorescence imaging; thus, these factors should be taken in account when selecting patients for ICG localization. The next study in preparation is to perform ICG localization without the use of microcoil. Different injection approaches are under consideration.

In the current study, we had the luxury of access to the guided therapeutic operating room with a CT scanner and cone-beam CT for intraoperative fluoroscopy. However, these technologies may not be readily available in the operating room for thoracic surgeons. Although most localization techniques reported to date have used percutaneous insertion of wires, dye, or contrast agents for localization, percutaneous CT-guided approaches pose some risks, such as radiation exposure, pneumothorax, and bleeding. ${ }^{8}$ Although techniques differ, critical air embolism has been reported with percutaneous CT-guided lung biopsy and should be considered as one of the potential complications during percutaneous insertion of markers. ${ }^{29}$ Dislodgement of wires and diffusion of dye and contrast agents are some of the technical challenges that have been reported. ${ }^{8}$ With newer technologies such as navigational bronchoscopy, transbronchial placement of markers have been attempted, but the data are still limited with moderate accuracy. ${ }^{30-34}$ Although navigational bronchoscopy-guided localization may seem less invasive, this approach still requires a fulldose thin-slice CT scan for construction of navigation images in addition to fluoroscopy during the bronchoscopy. Therefore, the cost cannot be ignored, and not all lesions within the lung are accessible. We have developed a transbronchial localization technique in an animal model that uses navigational bronchoscope and NIR thoracoscope together with ICG. ${ }^{18}$ Some of the advantages of using ICG in combination with the NIR thoracoscope compared with other injectable fluid include the depth of penetration and ease of visualization. A clinical trial using this technique is currently under preparation.

\section{CONCLUSIONS}

We have described a new multimodality approach for image-guided localization and minimally invasive resection of small pulmonary nodules using a NIR thoracoscope and ICG fluorescence. This is a safe and feasible minimally invasive approach for localization and resection of small and ground-glass nodules. It is a complementary technique to CT-guided microcoil localization.

\section{Webcast}

You can watch a Webcast of this AATS meeting presentation by going to: http://webcast.aats.org/2016/Video/ Tuesday/05-17-16_Room_337_0820_Ujiie-800.mp4.

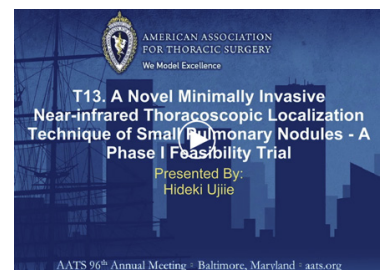

\section{Conflict of Interest Statement}

Authors have nothing to disclose with regard to commercial support.

The authors thank the clinical research coordinators, Alexandria Grindlay and Judy McConnell, for their contribution to the study, and Sam Santiago for radiology technologic support during the CT-guided procedure in the guided therapeutic operating room.

\section{References}

1. Canadian Cancer Society. Lung cancer statistics. Available at: http://www.cancer. $\mathrm{ca} /$ en/cancer-information/cancer-type/lung/statistics/?region $=$ on. Accessed May $24,2016$.

2. Henschke CI. Early lung cancer action project. Cancer. 2000;89:2474-82.

3. Diederich S, Thomas M, Semik M, Lenzen H, Roos N, Weber A, et al. Screening for early lung cancer with low-dose spiral computed tomography: results of annual follow-up examinations in asymptomatic smokers. Eur Radiol. 2004; 14:691-702.

4. Aberle DR, Adams AM, Berg CD, Black WC, Clapp JD, Fagerstrom RM, et al. Reduced lung-cancer mortality with low-dose computed tomographic screening. N Engl J Med. 2011;365:395-409.

5. Bendixen M, Jorgensen OD, Kronborg C, Andersen C, Licht PB. Postoperative pain and quality of life after lobectomy via video-assisted thoracoscopic surgery or anterolateral thoracotomy for early stage lung cancer: a randomised controlled trial. Lancet Oncol. 2016;17:836-44. 
6. Vannucci F, Gonzalez-Rivas D. Is VATS lobectomy standard of care for operable non-small cell lung cancer? Lung Cancer. 2016;100:114-9.

7. Suzuki K, Nagai K, Yoshida J, Ohmatsu H, Takahashi K, Nishimura M, et al. Video-assisted thoracoscopic surgery for small indeterminate pulmonary nodules: indications for preoperative marking. Chest. 1999;115: 563-8.

8. Saito H, Minamiya Y, Matsuzaki I, Tozawa K, Taguchi K, Nakagawa T, et al. Indication for preoperative localization of small peripheral pulmonary nodules in thoracoscopic surgery. J Thorac Cardiovasc Surg. 2002; 124:1198-202.

9. Powell TI, Jangra D, Clifton JC, Lara-Guerra H, Church N, English J, et al. Peripheral lung nodules: fluoroscopically guided video-assisted thoracoscopic resection after computed tomography-guided localization using platinum microcoils. Ann Surg. 2004;240:481-9.

10. Ujiie H, Kadota K, Chaft JE, Buitrago D, Sima CS, Huang J, et al. Solid predominant histologic subtype in resected stage I lung adenocarcinoma is an independent predictor of early, extrathoracic, multisite recurrence and of poor postrecurrence survival. J Clin Oncol. 2015;33: 2877-84.

11. Kadota K, Nitadori J, Sima CS, Ujiie H, Rizk NP, Jones DR, et al. Tumor spread through air spaces is an important pattern of invasion and impacts the frequency and location of recurrences after limited resection for small stage I lung adenocarcinomas. J Thorac Oncol. 2015;10:806-14.

12. Finley RJ, Mayo JR, Grant K, Clifton JC, English J, Leo J, et al. Preoperative computed tomography-guided microcoil localization of small peripheral pulmonary nodules: a prospective randomized controlled trial. J Thorac Cardiovasc Surg. 2015;149:26-31.

13. Mayo JR, Clifton JC, Powell TI, English JC, Evans KG, McWilliams AM, et al. Lung nodules: CT-guided placement of microcoils to direct video-assisted thoracoscopic surgical resection. Radiology. 2009;250:576-85.

14. Kha LC, Hanneman K, Donahoe L, Chung T, Pierre AF, Yasufuku K, et al. Safety and efficacy of modified preoperative lung nodule microcoil localization without pleural marking: a pilot study. J Thorac Imaging. 2016;31: $15-22$.

15. Donahoe LL, Nguyen ET, Chung TB, Kha LC, Cypel M, Darling GE, et al. CTguided microcoil VATS resection of lung nodules: a single-centre experience and review of the literature. J Thorac Dis. 2016;8:1986-94.

16. Templeton PA, Krasna M. Needle/wire lung nodule localization for thoracoscopic resection. Chest. 1993;104:953-4.

17. Zaman M, Bilal H, Woo CY, Tang A. In patients undergoing video-assisted thoracoscopic surgery excision, what is the best way to locate a subcentimetre solitary pulmonary nodule in order to achieve successful excision? Interact Cardiovasc Thorac Surg. 2012;15:266-72.

18. Anayama T, Qiu J, Chan H, Nakajima T, Weersink R, Daly M, et al. Localization of pulmonary nodules using navigation bronchoscope and a near-infrared fluorescence thoracoscope. Ann Thorac Surg. 2015;99:224-30.

19. Yasufuku K, Pierre A, Darling G, de Perrot M, Waddell T, Johnston M, et al. A prospective controlled trial of endobronchial ultrasound-guided transbronchial needle aspiration compared with mediastinoscopy for mediastinal lymph node staging of lung cancer. J Thorac Cardiovasc Surg. 2011;142: 1393-400.

20. Fujiwara M, Mizukami T, Suzuki A, Fukamizu H. Sentinel lymph node detection in skin cancer patients using real-time fluorescence navigation with indocyanine green: preliminary experience. J Plast Reconstr Aesthet Surg. 2009;62:e373-8.

21. Fujisawa Y, Nakamura Y, Kawachi Y, Otsuka F. Indocyanine green fluorescencenavigated sentinel node biopsy showed higher sensitivity than the radioisotope or blue dye method, which may help to reduce false-negative cases in skin cancer. $J$ Surg Oncol. 2012;106:41-5.

22. Namikawa K, Yamazaki N. Sentinel lymph node biopsy guided by indocyanine green fluorescence for cutaneous melanoma. Eur J Dermatol. 2011; 21:184-90.

23. Murawa D, Hirche C, Dresel S, Hünerbein M. Sentinel lymph node biopsy in breast cancer guided by indocyanine green fluorescence. Br J Surg. 2009;96: 1289-94.

24. Hutteman M, Mieog JSD, Van Der Vorst JR, Liefers GJ, Putter H, Lowik CW, et al. Randomized, double-blind comparison of indocyanine green with or without albumin premixing for near-infrared fluorescence imaging of sentinel lymph nodes in breast cancer patients. Breast Cancer Res Treat. 2011;127: 163-70.
25. Polom K, Murawa D, Nowaczyk P, Rho YS, Murawa P. Breast cancer sentinel lymph node mapping using near infrared guided indocyanine green and indocyanine green-human serum albumin in comparison with gamma emitting radioactive colloid tracer. Eur J Surg Oncol. 2012;38:137-42.

26. Crane LM, Themelis G, Buddingh KT, Harlaar NJ, Pleijhuis RG, Sarantopoulos A, et al. Multispectral real-time fluorescence imaging for intraoperative detection of the sentinel lymph node in gynecologic oncology. $J$ Vis Exp. 2010;20:e2225.

27. Hayashi T, Furukawa H, Oyama A, Funayama E, Saito A, Yamao T, et al. Sentinel lymph node biopsy using real-time fluorescence navigation with indocyanine green in cutaneous head and neck/lip mucosa melanomas. Head Neck. 2012;34:758-61.

28. Gilmore DM, Khullar OV, Jaklitsch MT, Chirieac LR, Frangioni JV, Colson YL. Identification of metastatic nodal disease in a phase 1 doseescalation trial of intraoperative sentinel lymph node mapping in non-small cell lung cancer using near-infrared imaging. J Thoracic Cardiovasc Surg. 2013; 146:562-70.

29. Tomiyama N, Yasuhara Y, Nakajima Y, Adachi S, Arai Y, Kusumoto M, et al. CTguided needle biopsy of lung lesions: a survey of severe complication based on 9783 biopsies in Japan. Eur J Radiol. 2006;59:60-4.

30. Endo M, Kotani Y, Satouchi M, Takada Y, Sakamoto T, Tsubota N, et al. CT fluoroscopy-guided bronchoscopic dye marking for resection of small peripheral pulmonary nodules. Chest. 2004;125:1747-52.

31. Sato M, Omasa M, Chen F, Sato T, Sonobe M, Bando T, et al. Use of virtual assisted lung mapping (VAL-MAP), a bronchoscopic multispot dye-marking technique using virtual images, for precise navigation of thoracoscopic sublobar lung resection. J Thorac Cardiovasc Surg. 2014;147:1813-9.

32. Asano F, Shindoh J, Shigemitsu K, Miya K, Abe T, Horiba M, et al. Ultrathin bronchoscopic barium marking with virtual bronchoscopic navigation for fluoroscopy-assisted thoracoscopic surgery. Chest. 2004;126:1687-93.

33. Krimsky WS, Minnich DJ, Cattaneo SM, Sarkar SA, Harley DP, Finley DJ, et al. Thoracoscopic detection of occult indeterminate pulmonary nodules using bronchoscopic pleural dye marking. J Community Hosp Intern Med Perspect. 2014;4.

34. Marino KA, Sullivan JL, Weksler B. Electromagnetic navigation bronchoscopy for identifying lung nodules for thoracoscopic resection. Ann Thorac Surg. 2016;102:454-7.

Key Words: fluorescence, lung cancer, image-guided surgery, indocyanine green, near-infrared, staging

\section{Discussion}

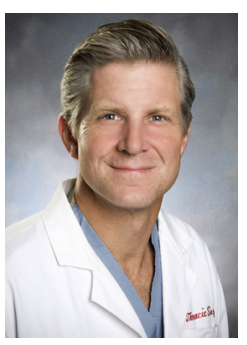

Dr Scott Swanson (Boston, Mass). That was an outstanding presentation and novel technique. I just have 1 housekeeping question. If you localized 19 of 20, how did you get 20 negative margins? What happened to that 20th lesion you couldn't find?

Dr Ujiie. Only 1 case had insufficient fluorescence imaging. In that case, we just used fluoroscopy for localizing the microcoil.

Dr Swanson. You didn't use the green, just the microcoil in 1 case?

Dr Ujiie. Yes. In this case there was insufficient ICG localization. Fluoroscopy was helpful to resect the lung specimen. 
Dr Swanson. Your surgeons are doing the coil and the ICG injection or is that a radiologist? How does that work in your institution?

Dr Ujiie. Dr Yasufuku and the radiologist performed the microcoil placement and the ICG injection.

Dr Swanson. The surgeons did?

Dr Ujiie. Yes, the surgeon and the radiologist.

Dr Swanson. In the operating room?

Dr Ujiie. Yes.

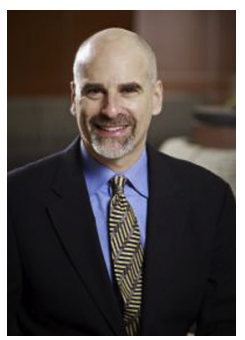

Dr Joseph Friedberg (Baltimore, $M d)$. For the few of us in the room who don't have a CT scanner in our operating room, how much time do you have between when you inject the dye and then you can subsequently still image it? How long does it stick around?

Dr Ujiie. Preoperative performance is 35 minutes, and after that, we move the patient to the operating table within maybe 10 minutes, then perform the general anesthetic intubation, and then perform the surgery.

Dr Friedberg. But if you can't do that, how long do you have? Do you have hours or minutes? Does it have to be that quick, or will the dye diffuse and you can't see it?

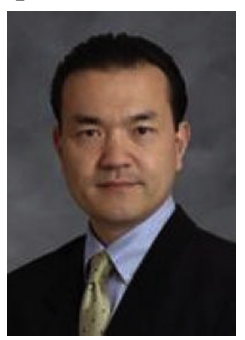

Dr Kazuhiro Yasufuku (Toronto, Ontario, Canada). I am a co-author. To answer your question, this was a feasibility study, so we did not want to see how long it will take to diffuse, but in our preclinical studies in our pig pseudo-tumor model, the ICG does stay for a couple of hours, even up to 3 hours, so if in an institute where they do not have the CT scan, potentially we can use this in the interventional radiology room before the surgery.

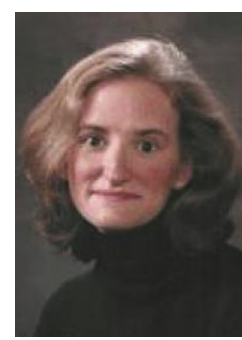

Dr Yolonda Colson (Boston, Mass). We have been able to see it up to 3 hours later. We also have been able to go up to approximately $3 \mathrm{~cm}$ deep. It gets really hard past that, so 2 to $2.5 \mathrm{~cm}$. One of my questions to both of you is that I think it matters a little bit on where you are injecting, if you are on the pleural side of the nodule or are you deep to the nodule, in terms of how that depth relates to seeing the lesion, and I'm interested in how you are planning it. Are you doing it on the deep side of the nodule by your microcoil or are you on the top surface so that you are closer to the pleura on these deep lesions?

Dr Kazuhiro Yasufuku. Because of the time, we were not able to show exactly how we do it. We first place the 19-gauge coaxial needle proximal to the ground-glass opacity, and we keep that coaxial needle right there, we don't move it, and through that 19-gauge, we place the 22-gauge needle where we place the coil, and immediately after that, we inject ICG in the same position. The idea is to keep the ICG proximal to the nodule so that when we are doing the resection, we can actually define where the ICG is so that we can go deep enough.

Dr Colson. That is what we have done, but I have seen people be very superficial on the other side, and they get a more defined circle on the pleura. So it will be interesting for us to figure out what our goal is: Do you want to be deep; do you want to be high. 